\title{
Androgens Increase Spine Synapse Density in the CA1 Hippocampal Subfield of Ovariectomized Female Rats
}

\author{
Csaba Leranth, ${ }^{1,2}$ Tibor Hajszan, ${ }^{1,3}$ and Neil J. MacLusky ${ }^{4}$ \\ Departments of ${ }^{1}$ Obstetrics and Gynecology and ${ }^{2}$ Neurobiology, Yale University School of Medicine, New Haven, Connecticut 06520-8063 ${ }^{3}$ Laboratory of \\ Molecular Neurobiology, Biological Research Center, Hungarian Academy of Sciences, H-6726 Szeged, Hungary, and ${ }^{4}$ Center for Reproductive Sciences, \\ Columbia University Medical School, New York, New York 10032
}

The effects of androgen on the density of spine synapses on pyramidal neurons in the CA1 area of the hippocampus were studied in ovariectomized (OVX) adult female rats. Treatment of OVX rats with testosterone propionate (TP; $500 \mu \mathrm{g} / \mathrm{d}$, s.c., $2 \mathrm{~d}$ ) significantly increased spine synapse density (from $0.661 \pm 0.016$ spine synapse $/ \mu \mathrm{m}^{3}$ in $\mathrm{OVX}$ rats to $1.081 \pm 0.018$ spine synapse/ $\mu \mathrm{m}^{3}$ after TP treatment). A smaller, but still statistically significant, increase in synapse density $\left(0.955 \pm 0.029\right.$ spine synapse $\left./ \mu \mathrm{m}^{3}\right)$ was observed in OVX animals after treatment with the nonaromatizable androgen dihydrotestosterone (DHT; $500 \mu \mathrm{g} / \mathrm{d}$, s.c., $2 \mathrm{~d}$ ). Administration of $1 \mathrm{mg}$ of letrozole, a powerful nonsteroidal aromatase inhibitor, $1 \mathrm{hr}$ before the steroid injections almost completely blocked the synaptic response to testosterone, resulting in a mean synapse density $\left(0.723 \pm 0.003\right.$ spine synapse $\left./ \mu \mathrm{m}^{3}\right)$ only slightly higher than in OVX control rats. By contrast, the response to DHT was unaffected by letrozole pretreatment. These data suggest that androgen secretion during the female reproductive cycle may contribute to cyclical changes in hippocampal synaptic density. They also indicate that androgen treatment may be as effective as estrogen replacement in reversing the decline in hippocampal CA1 spine synapses that follows loss of ovarian function. Induction of hippocampal synapse formation by androgen is not mediated entirely via intracerebral estrogen biosynthesis, however, because aromatase-independent mechanisms also significantly affect CA1 spine synapse density.

Key words: testosterone; spine synapse density; CA1; hippocampus; unbiased stereological calculation; dihydrotestosterone

\section{Introduction}

During the female reproductive cycle, the preovulatory surge of ovarian steroid hormone release induces an increase in the density of pyramidal cell dendritic spines and spine synapses in the CA1 subfield of the hippocampus (Gould et al., 1990; Woolley et al., 1990; Woolley and McEwen, 1992). This response is mediated at least in part by estrogen secretion: thus, in ovariectomized (OVX) females, estrogen treatment restores CA1 synapse density to levels comparable to those normally observed at proestrus (McEwen and Woolley, 1994; Leranth et al., 2000; Leranth and Shanabrough, 2001).

Testosterone is also produced by the rat ovary, circulating at levels substantially higher than those of estradiol (Rush and Blake, 1982). In males, maintenance of normal CA1 spine synapse density is dependent on the continued presence of androgen. Thus, orchidectomy reduces CA 1 synapse density by $\sim 50 \%$, an effect that is reversed by $2 \mathrm{~d}$ of androgen treatment (Leranth et al., 2003). These data are not necessarily indicative of the effects of testosterone in females, however, because the brain is sexually differentiated. The distributions of both estrogen (Rainbow et al.,

Received May 22, 2003; revised Nov. 6, 2003; accepted Nov. 19, 2003.

This work was supported by National Institutes of Health Grants MH60858 and NS42644.

Correspondence should be addressed to Dr. Csaba Leranth, Department of Obstetrics and Gynecology, Yale University School of Medicine, 333 Cedar Street, FMB 313, New Haven, CT 06520-8063. E-mail: csaba.leranth@yale.edu.

D0I:10.1523/JNEUROSCI.4516-03.2004

Copyright $\odot 2004$ Society for Neuroscience $\quad 0270-6474 / 04 / 240495-05 \$ 15.00 / 0$
1982; Brown et al., 1988) and androgen (Roselli, 1991; Xiao and Jordan, 2002) receptors in the brain are sexually dimorphic. Sex differences in the structure and function of the rodent hippocampus have been reported by a number of laboratories (Lewis et al., 1995; Patchev and Almeida, 1996; Tabibnia et al., 1999; Shors and Miesegaes, 2002). Administration of estradiol increases CA1 spine synapse density in OVX female rats (Leranth et al., 2000; Leranth and Shanabrough, 2001), but in castrate males the same treatment is without effect (Leranth et al., 2003). The effects of testosterone on the hippocampus could be similarly differentiated, resulting in divergent synaptic responses to androgen in the two sexes.

To investigate this possibility, we studied the effects of testosterone on CA1 spine synapse density in OVX female rats, using the experimental paradigm that we previously used in males (Leranth et al., 2003). To determine whether the response to testosterone includes a contribution from local estrogen biosynthesis, the effects of testosterone were compared with those of the nonaromatizable androgen $5 \alpha$ dihydrotestosterone (DHT). In addition, the effects of the androgens were examined after pretreatment with letrozole, an inhibitor of the aromatase enzyme required for conversion of testosterone to estradiol.

\section{Materials and Methods}

Animals. Female Sprague Dawley rats (240-270 gm; Charles River Laboratories, Wilmington, MA) were kept in individual cages on a $12 \mathrm{hr}$ light/dark cycle and provided with ad libitum access to water and rat chow. All animal protocols used in this study were in compliance with the 
National Institutes of Health Guide for the Care and Use of Laboratory animals and approved by the Institutional Animal Care and Use Committee of Yale University.

Surgery and hormonal manipulations. Animals were deeply anesthetized using a ketamine-xylazine cocktail ( $3 \mathrm{ml} / \mathrm{kg}$, i.m.; containing $25 \mathrm{mg}$ ketamine, $1.2 \mathrm{mg}$ xylazine, and $0.03 \mathrm{mg}$ acepromazine in $1 \mathrm{ml}$ saline) and ovariectomized. One week after OVX, rats received either testosterone propionate (TP; $500 \mu \mathrm{g} ; n=3$ ) or DHT ( $500 \mu \mathrm{g} ; n=3$ ) dissolved in sesame oil in the form of two subcutaneous injections separated by $24 \mathrm{hr}$. Control animals $(n=3)$ were OVX for the same length of time and then injected with the sesame oil injection vehicle. An additional nine animals were subdivided 1 week after OVX into the same three treatment groups (OVX plus vehicle, OVX plus TP, OVX plus DHT) with the exception that in these animals the steroid or vehicle injections were preceded by treatment with the aromatase inhibitor letrozole (1 mg dissolved in 200 $\mu \mathrm{l}$ 2.5\% carboxymethylcellulose, s.c.; Novartis AG, Basel, Switzerland) (Lewis et al., 1995). One hour was allowed to elapse between the letrozole and the androgen injections, to ensure blockade of aromatase activity before androgen treatment.

Tissue processing. Two days after the second androgen or vehicle injection, rats were killed under deep ether anesthesia by transcardial perfusion of heparinized saline followed by a fixative containing $4 \%$ paraformaldehyde and $1 \%$ glutaraldehyde in $0.1 \mathrm{~m}$ phosphate buffer (PB; $\mathrm{pH}$ 7.35). Brains were removed and postfixed for $2 \mathrm{hr}$ in the same fixative. The hippocampi were dissected out, divided into three pieces (septal, temporal, and mid portions), and vibratome sections $(100 \mu \mathrm{m})$ were cut perpendicular to the longitudinal axis of each tissue block. The sections were postfixed in $1 \%$ osmium tetroxide $(30 \mathrm{~min}$ ), dehydrated in ethanol (the $70 \%$ ethanol contained $1 \%$ uranyl acetate for $30 \mathrm{~min}$ ), and flat embedded in Araldite.

Synapse counts. Spine synapse density was calculated in all animal groups according to our standard protocol using unbiased stereological methods (Leranth et al., 2000; Leranth and Shanabrough, 2001). To assess possible changes in the volume of the tissue, a correction factor was calculated assuming that the hormonal treatments did not alter the total number of pyramidal cells (Rusakov et al., 1997). In all hippocampi, six or seven disector pairs (pairs of adjacent $2 \mu \mathrm{m}$ toluidine blue-stained semithin sections mounted on slides) were analyzed using the technique of Braendgaard and Gundersen (1986). The pyramidal cell density value (D) was calculated using a formula: $D=N / s T$, where $N$ is the mean disector score across all sampling windows, $T$ is the thickness of the sections $(2 \mu \mathrm{m})$, and $s$ stands for the length of the window. Based on these values, a dimensionless volume correction factor $k_{\mathrm{v}}$ was introduced: $k_{\mathrm{v}}=$ $D / D_{1}$, where $D_{1}$ is the main density across the groups of hippocampi. Thereafter, using the toluidine blue-stained semithin sections as guides, each block was trimmed to contain the same area, located between the middle and distal portion of the stratum radiatum (Fig. 1). Pairs of consecutive serial ultrathin sections ("reference" and "look-up") were cut from the vibratome sections taken from all parts of the hippocampus along its longitudinal axis. The section pairs were collected on Formvarcoated single-slot grids. Subsequently, digitized images were taken at a magnification of $11,000 \times$ in a Tecnai 12 transmission electron microscope furnished with an AMT Advantage 4.00 HR/HR-B CCD camera system. Identical regions in reference and look-up sections were identified using landmarks (myelinated fibers, large dendrites, or blood vessels) that did not change appreciably between neighboring sections because of their size. Areas occupied by potentially interfering structures were subtracted using the NIH Scion image-processing software.

To obtain a comparable measure of synaptic numbers, unbiased for possible changes in synaptic size, the disector technique was used (Sterio, 1984). Digitized electron micrographs were printed out, coded, and the code was not broken until the analysis was completed. Only those spine synapses were counted that were present in the reference section, but not in the look-up section (Fig. 2). To increase the efficiency of counting, the analysis was performed treating each reference section as a look-up section, and vice versa (Woolley and McEwen, 1992).

The density of spine synapses of pyramidal cell dendrites was calculated with the help of a reference grid superimposed on the electron microscopic prints. The disector volume (volume of reference) was the

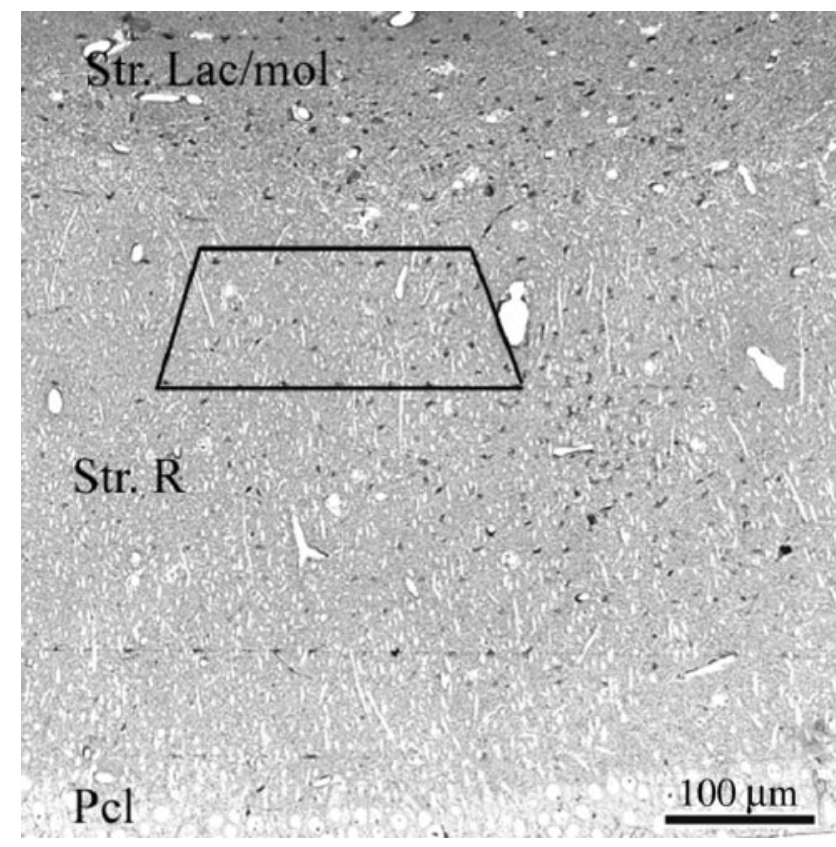

Figure 1. Light micrograph taken from a toluidine blue-stained, $2-\mu \mathrm{m}$-thick semithin section of the CA1 hippocampal subfield. The box labels the area from which the serial ultrathin sections were cut from each block. Str. Lac/mol, Stratum lacunosum moleculare; Str. R, stratum radiatum; $\mathrm{Pcl}$, pyramidal cell layer.

unit area of the reference grid multiplied by the distance between the upper faces of the reference and look-up sections (Braendgaard and Gundersen, 1986). Section thickness (average, $0.075 \mu \mathrm{m}$ ) was determined using the electron scattering technique (Small, 1968). The measured synaptic density values were divided by the volume correction factor $k_{\mathrm{v}}$. This correction provided a synaptic density estimate normalized with respect to the density of pyramidal cells and also accounted for possible changes in hippocampal volume.

Statistical analysis. At least five neuropil fields (each $80 \mu \mathrm{m}^{2}$ ) were photographed on each electron microscopic grid. With at least three grids (containing a minimum of two pairs of consecutive, serial ultrathin sections) prepared from each vibratome section (cut from the three portions of the hippocampus along its longitudinal axis), each animal provided at least $3 \times 3 \times 5 \times 2=90$ neuropil fields for evaluation, corresponding to a total section area of $7200 \mu \mathrm{m}^{2}$ (a total neuropil volume of $540 \mu \mathrm{m}^{3}$ ) per animal. The mean synapse densities for each animal were determined blind, independently by two different investigators and the results cross-checked to preclude systematic analytical errors. Individual mean synapse densities for each animal were used to calculate means and SEs for overall synapse density, in each experimental group. Results were analyzed by means of an initial two-way ANOVA, followed by the Scheffe test for comparison of individual group means.

\section{Results}

Pyramidal cell spine synapse density was significantly higher in the CA1 stratum radiatum of the androgen-treated animals than in the comparable region of the OVX females (Fig. 3). Treatment of OVX rats with TP increased mean CA1 spine synapse density by $\sim 64 \%$, from $0.661 \pm 0.016$ to $1.081 \pm 0.018$ synapse $/ \mu \mathrm{m}^{3}$. Treatment with the same dose of DHT also significantly increased spine synapse density, although the increase was less than that observed with TP. Treatment with the aromatase inhibitor letrozole did not affect spine synapse density in OVX females. Letrozole also had no effect on the response to the nonaromatizable androgen DHT: after DHT plus letrozole treatment, the mean density of CA1 spine synapses $(0.993 \pm 0.015$ synapse/ $\mu \mathrm{m}^{3}$ ) was indistinguishable from that in animals treated with 


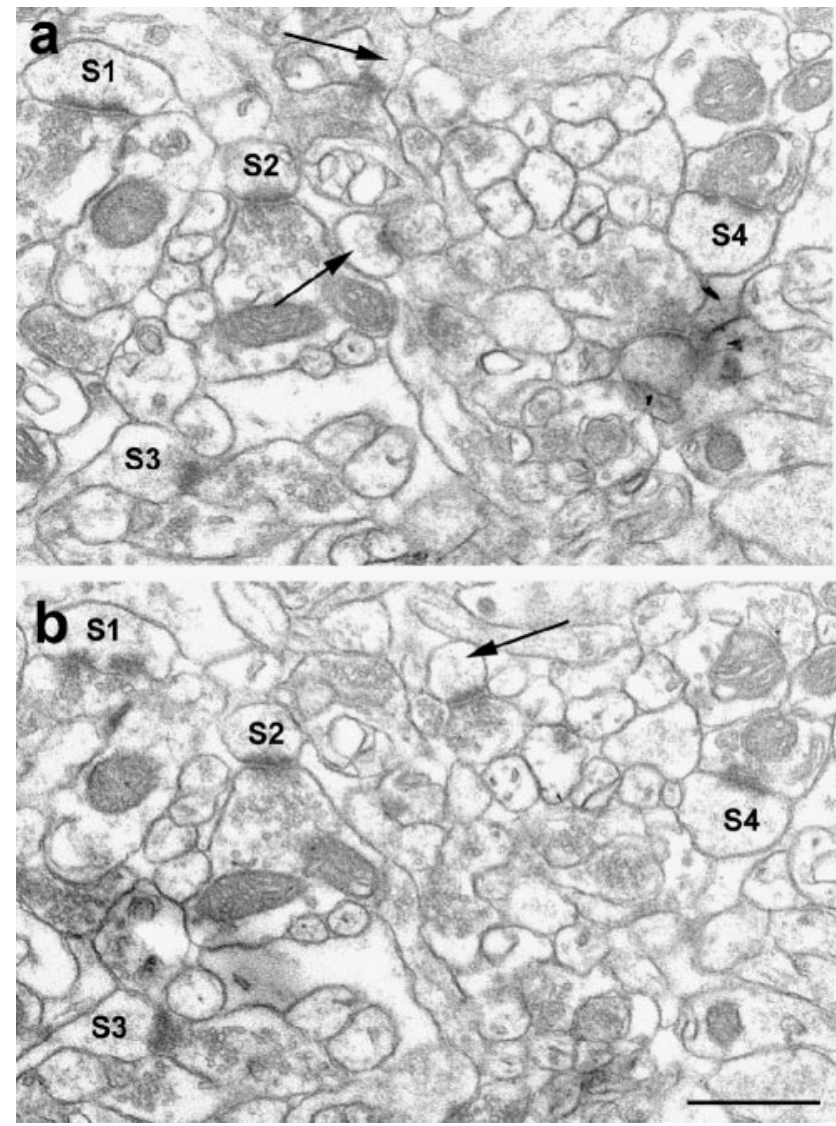

Figure 2. Electron micrographs demonstrate the same area on two consecutive, serial sections depicted from the stratum radiatum of the CA1 area. $a$ and $b$ show the reference and look-up sections, respectively. Labels S1-S4 mark spines that are in postsynaptic position in both sections. Only those spine synapses were counted that were seen just in one section (arrows). Scale bar, $1 \mu \mathrm{m}$.

DHT alone $\left(0.955 \pm 0.029\right.$ synapse/ $\left.\mu \mathrm{m}^{3}\right)$. The response to $\mathrm{TP}$, however, was markedly impaired by letrozole pretreatment. In the presence of letrozole, the effect of TP on CA1 spine synapse density was dramatically reduced, to a mean of only $0.723 \pm$ 0.003 synapse $/ \mu \mathrm{m}^{3}$. Synapse density in letrozole plus TP-treated animals remained slightly $(\sim 10 \%)$ but significantly higher than the levels observed in OVX vehicle-injected animals (Fig. 3).

\section{Discussion}

This study demonstrates that: (1) short-term treatment with testosterone propionate reverses the loss of CA1 area pyramidal spine synapses observed in OVX rats. (2) The nonaromatizable androgen dihydrotestosterone also increases CA1 spine synapse density, although it does not completely reproduce the effect of TP. (3) Administration of an aromatase inhibitor almost completely blocks the synaptic response to $\mathrm{TP}$, without affecting the response to DHT.

\section{Effects of gonadal steroids on CA1 pyramidal spine synapse density}

The role of estrogen as a modulator of CA1 pyramidal spine structure and spine synapse density is well established (Gould et al., 1990; Woolley et al., 1990; Woolley and McEwen, 1992; McEwen and Woolley, 1994). Previous work from our laboratory has demonstrated that testosterone, the principal gonadal steroid released by the testis, also has effects on the maintenance of hippocampal synapse density. Thus, gonadectomy reduces the num-

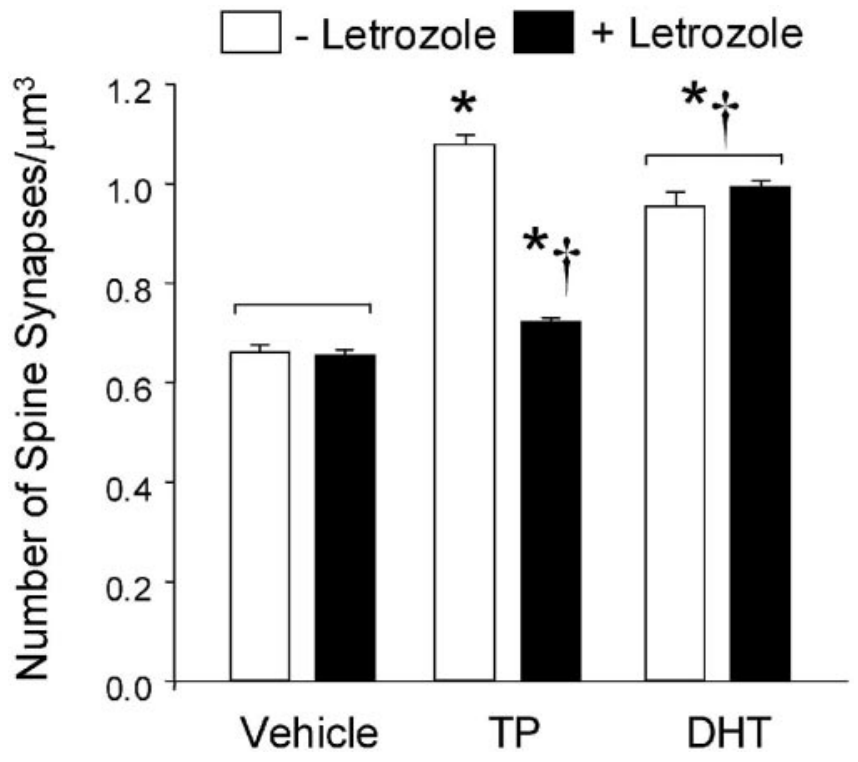

Figure 3. Pyramidal cell spine synapse densities in the CA1 stratum radiatum of 0VX rats. Results represent the means \pm SEM of the average synapse densities determined in three animals per treatment group. Open bars, An increase in spine synapse density was observed after TP treatment. A slightly smaller increase in synaptic density was observed in the DHTinjected animals. Significant differences were observed between the OVX plus DHT group and both the OVX plus vehicle controls and OVX plus TP animals. Solid bars, Pretreatment with letrozole (1 mg, s.c.) $1 \mathrm{hr}$ before the steroid or vehicle injections had no effect on synapse density in the OVX plus vehicle animals, almost completely blocked the response to TP, but had no effect on the response to DHT. Statistical analysis: two-way ANOVA: steroid effect, $F=64.7 ; \mathrm{df} 2,12$; $p<0.0001$. Letrozole effect, $F=19.8 ; \mathrm{df} 1,12 ; p<0.001$. Steroid $\times$ letrozole interaction; $F=$ $24.9 ; \mathrm{df} 2,12 ; p<0.0001$. ${ }^{*}$ Significantly different from $0 V X$ vehicle-injected rats; $†$ significantly different from OVX plus TP group, without letrozole pretreatment (Scheffe test; $p<0.05$ level). Histogram bars linked by square brackets are not significantly different from each another.

ber of CA1 dendritic spine synapses in males (Leranth et al., 2003), as it does in females (McEwen and Woolley, 1994). Treatment with estrogen reverses the decline in spine synapse density caused by ovariectomy in females (McEwen and Woolley, 1994; Leranth et al., 2000; Leranth and Shanabrough, 2001). However, estrogen does not have a significant effect in orchidectomized males (Leranth et al., 2003).

We have previously reported that testosterone replacement reverses the orchidectomy-induced decrease in CA1 spine synapse density in males (Leranth et al., 2003). The present experiments demonstrate that testosterone elicits a comparable effect in OVX females. The CA1 spine synapse density in the OVX plus TP group of the present study is comparable to values previously reported for this region of the brain in estrogen-replaced OVX females (Leranth et al., 2000; Leranth and Shanabrough, 2001), testosterone-replaced castrated males, or normal intact males (Leranth et al., 2003). Thus, in contrast to the effects of estrogen that are pronounced in females but insignificant in males, both sexes respond to androgen.

In males, the relative insensitivity to estrogen results in identical hippocampal synaptic responses to TP and DHT (Leranth et al., 2003). Thus, although testosterone is converted to estradiol in the brain of the male (Naftolin et al., 1975; Lieberburg and McEwen, 1977), maintenance of CA1 synapse density is not dependent on this pathway. In females, however, CA1 spine synapse density is estrogen-sensitive, so testosterone can potentially affect synapse density via either estrogen- or androgen-dependent mechanisms. In the present study, doses of TP and DHT that have previously been shown to produce equivalent effects in 
males (Leranth et al., 2003) induced different synaptic responses in females. Spine synapse density after DHT was slightly but significantly less than after TP (Fig. 3). We hypothesize that this reflects the potential for testosterone to be aromatized, thereby acting on both androgen and estrogen receptor systems, whereas DHT acts only on androgen-sensitive mechanisms. Consistent with this view, in the presence of letrozole, the response to testosterone was dramatically reduced, whereas that to DHT was not significantly impaired.

These data suggest that the effects of testosterone and DHT on CA1 synapse density in females, although numerically comparable, probably involve distinctly different mechanisms. Testosterone induces an increase in CA1 spine synapse density primarily via intermediate estrogen biosynthesis. The residual small effect of TP observed in the presence of letrozole probably reflects either the intrinsic androgenic activity of testosterone, or conversion to DHT within the brain (Lieberburg and McEwen, 1977). By contrast, although injections of DHT produce effects that are quantitatively almost as large as those of testosterone, this response is independent of aromatization.

The concept that estrogens and androgens may exert their effects through different mechanisms is supported by data indicating that androgen and estrogen receptors are differentially distributed in the rat hippocampus (Loy et al., 1988; Simerly et al., 1990; Kerr et al., 1995; Milner et al., 2001; Towart et al., 2003). It is also consistent with our recent observations that gonadal steroid-induced synaptic changes are differentially dependent on afferent hippocampal input. Elimination of subcortical afferents via transection of the fimbria-fornix completely abrogates the effects of estrogen on hippocampal CA1 spine synapse density in females (Leranth et al., 2000). In males, however, the effects of testosterone are only partially blocked by fimbria-fornix transection (Kovacs et al., 2003). These data suggest that effects of androgen may be at least partially mediated via neurons within the hippocampus, whereas responses to estrogen are dependent on the integrity of subcortical afferent pathways (Leranth et al., 2000; Lam and Leranth, 2003).

\section{Functional and clinical significance}

Fluctuations in hippocampal synapse density over the estrous cycle have been related primarily to the actions of the principal ovarian steroids, estradiol and progesterone (Gould et al., 1990; Woolley et al., 1990; Woolley and McEwen, 1992). The present data raise the possibility that androgens could also contribute to physiological changes in hippocampal synapse number in females, because circulating testosterone levels increase approximately fourfold at around the time of ovulation (Rush and Blake, 1982).

The ability of androgens to modulate pyramidal spine synapse density has important physiological ramifications. In hippocampal slices from OVX rats, testosterone has been demonstrated to increase excitatory postsynaptic potential amplitudes and CA1 population spike amplitudes (Smith et al., 2002). The hippocampus is vital for processing of mnemonic information: improvements in memory have been reported after androgen treatment in mice (Flood et al., 1995), as well as in both young (Postma et al., 2000; Ross et al., 2003) and postmenopausal (Wisniewski et al., 2002) women. Positive associations between endogenous androgen levels and cognitive performance have been reported in men (Barrett-Connor et al., 1999; Neave et al., 1999; Yaffe et al., 2002) and women (Barrett-Connor and Goodman-Gruen, 1999). By analogy with the effects of estrogen (Cordoba Montoya and Carrer, 1997; Luine, 1997), enhancement of cognitive func- tion by androgen may result, at least in part, from increased CA1 spine synapse density.

A corollary of the hypothesis that androgens are involved in maintenance of normal hippocampal structure is that withdrawal of androgen could have adverse effects on hippocampal function, perhaps contributing to age-related neurodegenerative disorders. Total androgen production decreases after the third decade of life, in both men and women (Labrie et al., 1997; Skalba et al., 2003). Androgens have been reported to have neuroprotective effects on hippocampal neurons (Bastianetto et al., 1999; Pike, 2001). Cognitive deficits in female mice expressing the human apolipoprotein E4 gene, a known risk factor for Alzheimer's disease, are reversed by androgen treatment (Raber et al., 2002); whereas in men, circulating testosterone concentrations have been reported to be lower in patients with dementia of the Alzheimer's type (Hogervorst et al., 2001).

In summary, these data indicate that androgens induce synapse formation in the CA1 subfield of the female rat hippocampus, via aromatase-independent as well as aromatase-dependent mechanisms. Increases in CA1 spine synapse density may contribute to the effects of androgens on hippocampal function, whereas loss of trophic responses to androgen may contribute to the etiology of age-related neurodegenerative disease, as endogenous androgen production declines.

\section{References}

Barrett-Connor E, Goodman-Gruen D (1999) Cognitive function and endogenous sex hormones in older women. J Am Geriatr Soc 47:1289-1293.

Barrett-Connor E, Goodman-Gruen D, Patay B (1999) Endogenous sex hormones and cognitive function in older men. J Clin Endocrinol Metab 84:3681-3685.

Bastianetto S, Ramassamy C, Poirier J, Quirion R (1999) Dehydroepiandrosterone (DHEA) protects hippocampal cells from oxidative stressinduced damage. Brain Res Mol Brain Res 66:35-41.

Braendgaard H, Gundersen HJ (1986) The impact of recent stereological advances on quantitative studies of the nervous system. J Neurosci Methods 18:39-78.

Brown TJ, Hochberg RB, Zielinski JE, MacLusky NJ (1988) Regional sex differences in cell nuclear estrogen-binding capacity in the rat hypothalamus and preoptic area. Endocrinology 123:1761-1770.

Cordoba Montoya DA, Carrer HF (1997) Estrogen facilitates induction of long term potentiation in the hippocampus of awake rats. Brain Res 778:430-438.

Flood JF, Farr SA, Kaiser FE, La Regina M, Morley JE (1995) Age-related decrease of plasma testosterone in SAMP8 mice: replacement improves age-related impairment of learning and memory. Physiol Behav 57:669-673.

Gould E, Woolley CS, Frankfurt M, McEwen BS (1990) Gonadal steroids regulate dendritic spine density in hippocampal pyramidal cells in adulthood. J Neurosci 10:1286-1291.

Hogervorst E, Williams J, Budge M, Barnetson L, Combrinck M, Smith AD (2001) Serum total testosterone is lower in men with Alzheimer's disease. Neuroendocrinol Lett 22:163-168.

Kerr JE, Allore RJ, Beck SG, Handa RJ (1995) Distribution and hormonal regulation of androgen receptor $(A R)$ and $A R$ messenger ribonucleic acid in the rat hippocampus. Endocrinology 136:3213-3221.

Kovacs E-G, MacLusky NJ, Leranth C (2003) Effects of testosterone on hippocampal CA1 spine synaptic density in the male rat are inhibited by fimbria-fornix transection. Neuroscience 122:807-812.

Labrie F, Belanger A, Cusan L, Gomez JL, Candas B (1997) Marked decline in serum concentrations of adrenal C19 sex steroid precursors and conjugated androgen metabolites during aging. J Clin Endocrinol Metab 82:2396-2402.

Lam TT, Leranth C (2003) Role of medial septum diagonal band of Broca cholinergic neurons in estrogen-induced spine synapse formation on hippocampal CA1 pyramidal cells of female rats. Eur J Neurosci 17:1-9.

Leranth C, Shanabrough M (2001) Supramammillary area mediates subcortical estrogenic action on hippocampal synaptic plasticity. Exp Neurol 167:445-450. 
Leranth C, Shanabrough M, Horvath TL (2000) Hormonal regulation of hippocampal spine synapse density involves subcortical mediation. Neuroscience 101:349-356.

Leranth C, Petnehazy O, MacLusky NJ (2003) Gonadal hormones affect spine synaptic density in the CA1 hippocampal subfield of male rats. J Neurosci 23:1588-1592.

Lewis C, McEwen BS, Frankfurt M (1995) Estrogen-induction of dendritic spines in ventromedial hypothalamus and hippocampus: effects of neonatal aromatase blockade and adult GDX. Brain Res Dev Brain Res 87:91-95.

Lieberburg I, McEwen BS (1977) Brain cell nuclear retention of testosterone metabolites, $5 \alpha$ - dihydrotestosterone and estradiol- $17 \beta$ in adult rats. Endocrinology 100:588-597.

Loy R, Gerlach JL, McEwen BS (1988) Autoradiographic localization of estradiol-binding neurons in the rat hippocampal formation and entorhinal cortex. Brain Res 467:245-251.

Luine VN (1997) Steroid hormone modulation of hippocampal dependent spatial memory. Stress 2:21-36.

McEwen BS, Woolley CS (1994) Estradiol and progesterone regulate neuronal structure and synaptic connectivity in adult as well as developing brain. Exp Gerontol 29:431-436.

Milner TA, McEwen BS, Hayashi S, Li CJ, Reagan LP, Alves SE (2001) Ultrastructural evidence that hippocampal alpha estrogen receptors are located at extranuclear sites. J Comp Neurol 429:355-371.

Naftolin F, Ryan KJ, Davies IJ, Reddy VV, Flores F, Petro Z, Kuhn M, White RJ, Takaoka Y, Wolin L (1975) The formation of estrogens by central neuroendocrine tissue. Recent Prog Horm Res 31:295-319.

Neave N, Menaged M, Weightman DR (1999) Sex differences in cognition: the role of testosterone and sexual orientation. Brain Cogn 41:245-262.

Patchev VK, Almeida OF (1996) Gonadal steroids exert facilitating and glucocorticoid-mediated transcriptional regulation of corticotropinreleasing hormone and corticosteroid receptor genes in rat brain. J Neurosci 16:7077-7084.

Pike CJ (2001) Testosterone attenuates beta-amyloid toxicity in cultured hippocampal neurons. Brain Res 919:160-165.

Postma A, Meyer G, Tuiten A, van Honk J, Kessels RP, Thijssen J (2000) Effects of testosterone administration on selective aspects of objectlocation memory in healthy young women. Psychoneuroendocrinology 25:563-575.

Raber J, Bongers G, LeFevour A, Buttini M, Mucke L (2002) Androgens protect against apolipoprotein E4-induced cognitive deficits. J Neurosci 22:5204-5209.

Rainbow TC, Parsons B, McEwen BS (1982) Sex differences in rat brain oestrogen and progestin receptors. Nature (Lond) 300:648-649.

Roselli CE (1991) Sex differences in androgen receptors and aromatase activity in microdissected regions of the rat brain. Endocrinology 128:1310-1316.
Ross JL, Roeltgen D, Stefanatos GA, Feuillan P, Kushner H, Bondy C, Cutler Jr GB (2003) Androgen-responsive aspects of cognition in girls with Turner syndrome. J Clin Endocrinol Metab 88:292-296.

Rusakov DA, Richter-Levin G, Stewart MG, Bliss TV (1997) Reduction in spine density associated with long-term potentiation in the dentate gyrus suggests a spine fusion-and-branching model of potentiation. Hippocampus 7:489-500.

Rush ME, Blake CA (1982) Serum testosterone concentrations during the 4 -day estrous cycle in normal and adrenalectomized rats. Proc Soc Exp Biol Med 169:216-221.

Shors TJ, Miesegaes G (2002) Testosterone in utero and at birth dictates how stressful experience will affect learning in adulthood. Proc Natl Acad Sci USA 99:13955-13960.

Simerly RB, Chang C, Muramatsu M, Swanson LW (1990) Distribution of androgen and estrogen receptor mRNA-containing cells in the rat brain: an in situ hybridization study. J Comp Neurol 294:76-95.

Skalba P, Wojtowicz M, Sikora J (2003) Androgen and SHBG serum concentrations in late post-menopause women. Med Sci Monit 9:CR152156.

Small JV (1968) Measurement of section thickness. In: Proceedings of the European conference on electron microscopy, pp 609-610, Rome: Tipographia Poliglotta Vatican.

Smith MD, Jones LS, Wilson MA (2002) Sex differences in hippocampal slice excitability: role of testosterone. Neuroscience 109:517-530.

Sterio DC (1984) The unbiased estimation of number and sizes of arbitrary particles using the disector. J Microsc 134 (Pt 2):127-136.

Tabibnia G, Cooke BM, Breedlove SM (1999) Sex difference and laterality in the volume of mouse dentate gyrus granule cell layer. Brain Res 827:41-45.

Towart LA, Alves SE, Znamensky V, Hayashi S, McEwen BS, Milner TA (2003) Subcellular relationships between cholinergic terminals and estrogen receptor-alpha in the dorsal hippocampus. J Comp Neurol 463:390-401.

Wisniewski AB, Nguyen TT, Dobs AS (2002) Evaluation of high-dose estrogen and high-dose estrogen plus methyltestosterone treatment on cognitive task performance in postmenopausal women. Horm Res 58:150-155.

Woolley CS, McEwen BS (1992) Estradiol mediates fluctuation in hippocampal synapse density during the estrous cycle in the adult rat. J Neurosci 12:2549-2554.

Woolley CS, Gould E, Frankfurt M, McEwen BS (1990) Naturally occurring fluctuation in dendritic spine density on adult hippocampal pyramidal neurons. J Neurosci 10:4035-4039.

Xiao L, Jordan CL (2002) Sex differences, laterality, and hormonal regulation of androgen receptor immunoreactivity in rat hippocampus. Horm Behav 42:327-336.

Yaffe K, Lui LY, Zmuda J, Cauley J (2002) Sex hormones and cognitive function in older men. J Am Geriatr Soc 50:707-712. 